\title{
OS USOS DA IDEIA DE LUTA PELA EXISTÊNCIA NA PRODUÇÃO INTELECTUAL DO SÉCULO XIX
}

\author{
Raick de Jesus Souza *
}

\begin{abstract}
Resumo: O evolucionismo foi certamente a maior e a mais transformadora revolução paradigmática ocorrida no campo intelectual do Ocidente durante século XIX. Um dos conceitos que maior celeuma provocou na circulação das ideias evolucionistas foi o de "luta pela existência". O objetivo central desta investigação é compreender os diversos significados disponíveis durante o século XIX para a ideia de "luta pela existência" tanto no campo intelectual quanto científico. Usaremos como bases os trabalhos de intelectuais ligados ao campo científico - Charles Darwin, Herbert Spencer e Augusto Miranda de Azevedo - e intelectual - Silvio Romero e Araripe Junior. O caminho adotado é análise contextual das diversas ocorrências do conceito evolucionista produção intelectual brasileira durante a segunda metade do Oitocentos.
\end{abstract}

Palavras-chave: Campo intelectual; Evolucionismo; Naturalismo.

Abstract: Evolutionism was certainly the largest and most transformative paradigmatic revolution in the intellectual field of the West during the nineteenth century. One of the most striking concepts provoked in the circulation of evolutionist ideas was the "struggle for life". The central objective of this research is to understand the various meanings available during the nineteenth century for the idea of "struggle for existence" in both the intellectual and scientific fields. We will use as bases the works of intellectuals linked to the scientific field - Charles Darwin, Herbert Spencer

\footnotetext{
* Mestre em História das Ciências e da Saúde pela Casa de Oswaldo Cruz/FIOCRUZ; graduado em Licenciatura Plena em História pela Universidade Estadual do Sudoeste da Bahia Ï UESB. Pesquisa patrocinada pela Fundação Oswaldo Cruz. raickdjs@ hotmail.com.
} 
and Augusto Miranda de Azevedo - and intellectual - Silvio Romero and Araripe Junior. The path adopted is a contextual analysis of the various occurrences of the evolutionist concept of Brazilian intellectual production during the second half of the 19th century.

Keywords: Intellectual field; Evolutionism; Naturalism.

Usaremos como base os estudos realizados por Charles Darwin e Herbert Spencer, por crermos serem esses dois autores os mais expressivos intelectuais que fizeram uso da noção evolutiva de luta pela existência na caracterização da interação das espécies vivas com as outras espécies e com o meio no qual as mesmas encontravam-se inseridas. A interface entre o pensamento social brasileiro e os autores evolucionistas encontram-se presentes nas produções científicas e intelectuais que eram produzidas e que circulavam nos principais círculos letrados do país durante a segunda metade do século XIX.

Com relação aos intelectuais brasileiros, usaremos como base as interpretações desenvolvidas por Silvio Romero e Araripe Junior, evidenciando os diversos usos e significados que a noção evolutiva de luta pela existência assumiram em suas respectivas produções.

Por fim, realizaremos uma apresentação de como a noção de luta pela existência apareceu em outros autores brasileiros e estrangeiros, com o fito de compreendermos melhor quais eram os possíveis significados que este conceito poderia assumir no cenário letrado mais amplo.

\section{A ideia de luta pela existência nos clássicos evolucionistas: Darwin e Spencer}

Charles Robert Darwin nasceu Shrewsbury, na Inglaterra, em 1809, e foi um dos mais importantes nomes ligados ao movimento evolucionista do século XIX. Em 1831, embarcou em uma viagem exploratória ao redor do mundo no navio Beagle, no qual regressou em 1836, tendo passado por diversos países, entre eles o Brasil em 1832. Publicou mais de vinte anos depois seu mais importante trabalho, The origin of species (1859) no qual lançou uma das mais revolucionárias teorias já elaboradas no Ocidente, a saber, a teoria da evolução por seleção natural. Nesse livro de 1859, o naturalista

\section{Flistorturias}


inglês discutiu os princípios, as causas e as razões da vida, concluindo ser: a) todas as espécies vivas tanto do reino animal quanto vegetal proveniente de um mesmo ancestral; b) a mutabilidade das espécies; e, c) a seleção natural e seu corolário, a seleção dos mais adaptados, a luta pela sobrevivência e a hereditariedade dos caracteres. Reservou-se nesse trabalho a discutir apenas mais detidamente as leis da seleção natural entre os animais e plantas domesticados e aqueles observados em sua viagem. Com relação à espécie humana, publicou em 1871 The descente of man, and Selection in relation to Sex, no qual concluiu serem todas as espécies humanas submetidas às mesmas leis que as demais espécies vivas.

De acordo com Richard Dawkins (2009), o evolucionismo, especialmente a partir da publicação de The origin of specie, foi uma das maiores ñrevoluções paradigmáticasò experimentadas pelo Ocidente, se usarmos como parâmetro a ideia de ñparadigmaò proposta por Thomas Kunh. Peter Bowler defendeu ao longo de sua obra $A$ revolução não-Darwiniana: Reinterpretando um mito histórico, que um dos maiores equívocos nos estudos acerca da circulação das ideias de Darwin é a associação acrítica do Darwinismo com o Evolucionismo. De acordo com Bowler, desde que veio à lume, A origem das espécies foi recebido de forma controversa por parte dos intelectuais e cientistas. A recorrente associação das ideias de Darwin com a própria ideia de evolucionismo, fez emergir o que o autor chamou de ñDarwinismo não-Darwinianoò, ou seja, um modelo de evolucionismo, que em muitos pontos diverge das ideias pensadas por Darwin acerca do processo evolutivo das espécies.

Em A origem das espécies de 1859, o naturalista inglês propôs um modelo interpretativo para o processo de surgimento e variação das diversas espécies vivas existentes e já extintas. É importante notar a atenção especial que Darwin deu a ideia de luta pela existência no interior de sua teoria. A luta pela existência é capital em seu conjunto interpretativo, uma vez que, faz parte dos dispositivos de preservação das espécies e variação das mesmas. Já na introdução de seu livro, Darwin justificou quais foram as possíveis reflexões que lhe levaram a construção de sua teoria, e, é, exatamente nesse momento que entrevemos pela primeira vez sua compreensão acerca desse conceito. São inegáveis as repercussões que essas ideias tiveram nos diversos campos intelectuais do mundo ocidental. 
[...] Consideraremos a luta pela existência entre os seres organizados em todo o mundo, luta que deve inevitavelmente fluir da progressão geométrica do seu aumento em número. É a doutrina de Malthus aplicada a todo o reino animal e a todo o reino vegetal. Como nascem muitos mais indivíduos de cada espécie, que não podem subsistir; como, por consequência, a luta pela existência se renova a cada instante, segue-se que todo o ser que varia, ainda que pouco, de maneira a tornar-se-lhe aproveitável tal variação, tem maior probabilidade de sobreviver, este ser é também objeto de uma seleção natural. Em virtude do princípio tão poderoso da hereditariedade, toda a variedade objeto da seleção tenderá a propagar a sua nova forma modificada (DARWIN, 2003:16-17).

Nota-se de antemão que em relação à noção de luta pela existência, Darwin diz ter bebido no estudo de Thomas Malthus. São deveras curiosas as diversas referências que o naturalista faz do reverendo também inglês, em especial, ao seu trabalho An Essay on the principle of population (1789), no qual o líder anglicano discutiu sua teoria do crescimento populacional e da diminuição das reservas de recursos alimentares per capita.

A luta pela existência é o seu terceiro capítulo em The origin of species, de um total de quinze. Logo na entrada desse capítulo, Darwin mostrou a capitalidade da ideia de luta pela existência para o processo de variação e perpetuação das espécies. O cientista inglês afirmou que:

[...] como é que as variedades, que eu chamo espécies nascentes, acabaram por se converter em espécies verdadeiras e distintas, as quais, na maior parte dos casos, diferem evidentemente muito mais umas das outras que as variedades de uma mesma espécie; como se formam estes grupos de espécies, que constituem o que se chamam gêneros distintos, e que diferem mais uns dos outros que as espécies do mesmo gênero? Todos estes efeitos, como explicaremos de maneira mais minuciosa no capítulo seguinte, dimanam de uma causa: a luta pela existência. Devido a esta luta, as variações, por mais fracas que sejam e seja qual for a causa de onde provenham, tendem a preservar os indivíduos de uma espécie e transmitem-se ordinariamente à descendência logo que sejam úteis a esses indivíduos nas suas relações infinitamente complexas com os outros seres organizados e com as condições físicas da vida. Os descendentes terão, por si mesmo, em virtude deste fato, maior probabilidade em persistir; porque, dos indivíduos de uma espécie nascidos periodicamente, um pequeno número pode sobreviver. Dei a este princípio, em virtude do qual uma variação, por insignificante que

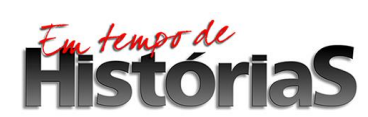

(PPGHIS/UnB) No. 34, Brasília, Jan - Jul 2019 ISSN 2316-1191 
seja, se conserva e se perpetua, se for útil, o nome de seleção natural, para indicar as relações desta seleção com a que o homem pode operar. Mas a expressão que M. Herbert Spencer emprega: «a persistência do mais apto», é mais exata e algumas vezes mais cômoda. Vimos que, devido à seleção, o homem pode certamente obter grandes resultados e adaptar os seres organizados às suas necessidades, acumulando as ligeiras, mas úteis variações que lhe são fornecidas pela natureza. Mas a seleção natural, como veremos mais adiante, é um poder sempre pronto a atuar; poder tão superior aos fracos esforços do homem como as obras da natureza são superiores às da arte (DARWIN, 2003:76).

Em seu primeiro subitem, explicou as razões também do emprego do conceito de luta pela existência de forma figurativa. Concluiu que a luta pela existência resultava inevitavelmente da rapidez com que todos os seres organizados tendem a multiplicar-se. Todo o indivíduo que, durante o tempo natural da vida, produz muitos ovos ou muitas sementes, deve ser destruído em qualquer período da sua existência, ou durante uma estação qualquer, porque, de outro modo, dando-se o princípio do aumento geométrico, o número dos seus descendentes tornar-se-ia tão considerável, que nenhum país ou região os poderia alimentar. Também, como nascem mais indivíduos que os que podem viver, devem existir, em cada caso, luta pela existência, quer com outro indivíduo da mesma espécie, quer com indivíduos de espécies diferentes, quer com as condições físicas da vida. Informou ainda que:

Não há exceção nenhuma à regra que se todo o ser organizado se multiplicasse naturalmente com tanta rapidez, e não fosse destruído, a terra em breve seria coberta pela descendência de um só par. $\mathrm{O}$ próprio homem, que se produz tão lentamente, veria o seu número dobrado todos os vinte e cinco anos, e, nesta proporção, em menos de mil anos, não haveria espaço suficiente no Globo onde pudesse conservar-se de pé (DARWIN, 2003:78-79).

Darwin explicou que a ação do meio externo, a exemplo da ação do clima, influencia diretamente na luta pela existência. Confessou que à primeira vista, parecia que a ação do clima é absolutamente independente da luta pela existência; mas argumentava que é necessário lembrar que as variações climatéricas atuam diretamente sobre a quantidade de nutrientes disponíveis, e produzem assim a mais viva luta entre os

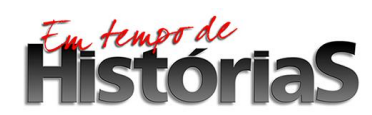

(PPGHIS/UnB) No. 34, Brasília, Jan - Jul 2019 ISSN 2316-1191 
indivíduos, quer da mesma espécie, quer de espécies distintas, que se nutrissem dos mesmos gêneros de alimentos e que habitam as mesmas regiões (DARWIN, 2003:83). Com relação às doenças, sugeriu que as epidemias podem acometer mais facilmente quando uma mesma espécie ocupa uma pequena zona, desenvolvendo assim uma ñuta entre parasita e presaò (DARWIN, 2003:84). Seguiu analisando as disputas existentes entre diversas espécies do reino vegetal e animal que são provocadas pela disputa em torno da obtenção dos recursos necessários a subsistência. Por fim, o autor concluiu que a luta pela existência é mais ñencarniçadaò quando disputada pelos indivíduos da mesma espécie:

Nada mais fácil que ensaiar assim, em imaginação, o procurar a uma espécie certas superioridades sobre uma outra; mas, na prática, é mais que provável que não soubéssemos o que teríamos a fazer. Isto só bastaria para nos convencer da nossa ignorância sobre as relações mútuas que existem entre todos os seres organizados; é uma verdade que nos é tão necessária como difícil de compreender. Tudo o que podemos fazer, é lembrar-nos a todo o momento que todos os seres organizados se esforçam continuamente por se multiplicar segundo uma progressão geométrica; que cada um deles em certos períodos da vida, durante certas estações do ano, no decurso de cada geração ou em certos intervalos, deve lutar pela existência e estar exposto a uma grande destruição. $O$ pensamento desta luta universal provoca tristes reflexões, mas podemos consolar-nos com a certeza de que a guerra não é incessante na natureza, que o medo é desconhecido, que a morte está geralmente pronta, e que são os seres vigorosos, sãos e felizes, que sobreviverão e se multiplicarão (DARWIN, 2003:92, grifo nosso).

Darwin argumentava que, a partir da luta pela existência, seriam garantidas as perpetuações dos seres mais vigorosos, sãos e felizes. Essas mesmas ideias seriam retomadas, em certa medida, em seu trabalho A origem do homem e a seleção sexual (1871) publicado doze anos depois de A origem das espécies.

Em seu trabalho de 1871, Darwin se deteve a explicar, como o homem e certos mamíferos superiores, possuíam estruturas homologas, que são melhor explicadas pela origem comum. Somente nos capítulos finais, depois de discutida a questão da seleção sexual em vários grupos animais, é que o cientista analisou as origens e as variações das ñaçasò humanas. Quando discutiu como o homem se desenvolveu de algumas formas

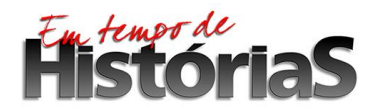

(PPGHIS/UnB) No. 34, Brasília, Jan - Jul 2019 ISSN 2316-1191 
ñnferioresò, incluindo não apenas os seres de outras espécies, como também os símios e os diversos antropomorfos no qual incluía os ancestrais humanoides, reafirmou a importância da variabilidade das espécies e da luta pela existência para as respectivas perpetuações dos seres mais desenvolvidos. Com relação à ação direta e definitiva da mudança de condições ambientais, escreveu que:

[...] Não se pode negar que condições mudadas produzem efeitos sobre organismos de todo gênero, efeitos estes que muitas vezes são consideráveis. À primeira vista parece provável que com um tempo suficiente se obterá resultados invariáveis. Mas não consegui obter uma prova cabal em apoio desta suposição; por outro lado, podem ser contrapostas válidas razões, ao menos no que diz respeito às numerosas estruturas cuja adaptação se dá para fins particulares. Contudo, não pode haver dúvidas de que a mudança das condições produz uma quantidade quase indefinida de variabilidade flutuante, que de qualquer modo torna toda estrutura flexível (DARWIN, 1974:44).

Com relação à primazia do homem na luta pela existência em comparação com as demais espécies, informou que, ñembora no estado atualmente mais atrasado, o homem é não obstante o animal mais potente que jamais apareceu sobre a terraò (DARWIN, 1974:63-64). Afirmou ainda que, embora as capacidades intelectuais e os usos sociais devam ser vistos como capitais para sua sobrevivência, seria preciso considerado em conjunto a força física.

Concluiu o seu trabalho afirmando que, em primeira ordem, a capacidade intelectual seria a maior ñarmaò do homem na luta pela existência, o que lhe permitia contrabalançar em muitos casos a fragilidade frente ao meio, podendo também servir para prestar serviço a seus companheiros, e em muitos casos garantir a defesa da integridade física de seus aliados, o que de forma alguma inviabilizaria ou amenizaria os diversos conflitos existentes entre indivíduos ou grupos. Afirmava que, a capacidade intelectual, somada as qualidades físicas e sexuais, garantiria a partir da transmissão de caracteres genéticos à perpetuação das espécies e à seleção natural dos mais adaptados (DARWIN, 1974:81-82).

\section{Fistotorias}

(PPGHIS/UnB) No. 34, Brasília, Jan - Jul 2019 ISSN 2316-1191 
Nesse último trabalho, Darwin manteve intenso debate com outros homens de letras de seu tempo, dentre eles, Herbert Spencer, grande nome do evolucionismo e que grande importância exerceu no cenário intelectual brasileiro, sobretudo, pela sua ênfase na aplicação da teoria da seleção natural à dimensão social.

Segundo Henrique Lins de Barros, a extrapolação das ideias evolucionistas no campo social, ou seja, a utilização de ideias importadas do darwinismo para tempos históricos de apenas alguns milhares de anos, fez surgir uma anomalia no pensamento ocidental, conhecido como Darwinismo social. O Darwinismo social se utilizou da ideia de evolução por seleção natural, associando ao desenvolvimento material e cultural das sociedades, ao processo de hierarquização das raças, com a conclusão de que o homem branco era superior, sob o aspecto biológico, aos demais povos (DOMINGUES et al, 2003:13).

Herbert Spencer (1820-1903) foi um filósofo, biólogo e etnógrafo inglês ligado a divulgação do movimento evolucionista. De acordo com Brian Holmes (1994), a aplicação dos preceitos biológicos darwinistas, sobretudo, a partir de A origem das espécies (1859) na interpretação feita por Spencer das questões psicológicas, sociológicas, biológicas, éticas e educacionais das populações, é perceptível na maior parte de seus trabalhos. Outros estudiosos como Lilian Al-Chueyr Pereira Martins (2004) e Gustavo Caponi (2014), identificaram as influências de outros autores naturalistas no pensamento filósofo. A primeira autora demonstrou a forte ligação entre o pensamento spenceriano e o neolamarquismo, e o segundo autor, por sua vez, percebeu a junção entre as ideias de Darwin e Curvier no conjunto da doutrina spenceriana.

Spencer teve uma vida intelectual ativa. A primeira vez que articulou as ideias evolutivas em seus estudos foi em seu ensaio Progress: Itố Law and Cause, publicado em 1857. Nesse estudo, o filósofo inglês propôs um conjunto interpretativo de ideias que explicava as leis e as causas gerais que determinam o progresso humano e o desenvolvimento dos agrupamentos populacionais. Partiu do pressuposto de que a lei inexorável do progresso era a passagem entre o homogêneo para o heterogêneo (SPENCER, 2002:15). O cientista inglês argumentou que a diferenciação é uma das leis

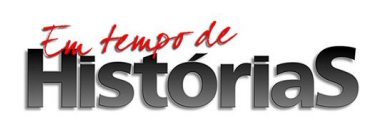

(PPGHIS/UnB) No. 34, Brasília, Jan - Jul 2019 ISSN 2316-1191 
que geram não apenas as substâncias vivas, como todos os seres inanimados que ocupam o cosmo. Sua investigação buscou, a partir da dedução, compreender os diversos estágios de diferenciação dos elementos que compõe o cosmo, sobretudo, as espécies vivas. O intelectual demonstrou enorme conhecimento das leis da Física, da Etnologia, da Botânica, das Artes e da História.

Analisando o desenvolvimento da teoria evolucionista no campo intelectual e científico, Michael Ruse (1999) concluiu que muitas das convergências entre Darwin e Spencer no que diz respeito às ideias biológicas, também podem ser vistas em suas concepções acerca do progresso social. Concordamos com Ruse no que diz respeito ao trânsito $\ddot{i}$ apropriações e ajustes $\ddot{i}$ de ideias entre esses dois personagens. Notamos ainda a incorporação da ideia de luta pela existência por Spencer após a publicação de The origin of species (1859) e a modificação feita por Darwin de mais ñadaptadoò para mais ñaptoò após os estudos das obras de Spencer.

Spencer considerava a seleção natural e seus correlatos importantes na evolução das espécies, porém, não conferia a ela uma primazia. Acreditava, assim como o próprio Darwin, que outros fatores deveriam ser considerados, como a ação dos usos e desusos e da transmissão de caracteres. Afirmou em seu trabalho The inadequacy of natural selection: The contemporary review, de 1893, que a seleção natural, ou propriamente, a sobrevivência do mais apto, é exclusivamente operante no mundo vegetal e animal. Porém, quando aplicada às espécies de tipo mais evoluído, os seus efeitos são em grau crescente envolvidos com aqueles produzidos por heranças de caracteres adquiridos, dessa forma, aos tipos mais evoluídos, a principal ação de diferenciação é a transmissão hereditária propriamente dita.

\section{A ideia de luta pela existência nos clássicos brasileiros: Silvio Romero e Araripe Junior}

Silvio Vasconcelos de Silveira Romero (1851-1914) foi um advogado, jornalista, crítico literário, ensaísta, poeta, historiador, filósofo, cientista político, 
escritor, professor e político brasileiro. Diplomou-se em Direito em 1873 pela Faculdade de Direito do Recife. Foi eleito pela primeira vez em 1876 como deputado provincial por Estância, Sergipe. Entre 1881 e 1910 lecionou Filosofia no Colégio Pedro II. Fez parte da fundação da Academia Brasileira de Letras em 1897. Atuou como deputado federal entre os anos de 1901 e 1902 pelo Partido Republicano, estando envolvido no processo de revisão do Código Civil. Durante toda a sua carreira, envolveu-se em diversas controvérsias intelectuais, sobretudo, na imprensa, onde atuou de forma ativa entre os anos de 1870 e 1912.

Na narrativa de Silvio Romero, apareceu uma concepção hierarquizada das raças, onde o elemento branco encontra-se situado ao topo da escala. $\mathrm{O}$ ñdesaparecimentoò das comunidades nativas americanas é explicado pelas suas baixas taxas populacionais e pelo seu atraso frente ao processo de colonização, tendo sido gradativamente suplantados pelos mais ñfortesò A ideia de luta pela existência encontra-se tematizada em sua obra na clara oposição entre o civilizado e o selvagem. A redução dos povos nativos era sintoma da disputa em torno da ocupação e utilização do território a partir da colonização europeia e da introdução do trabalho escravo. Em suas próprias palavras, ña raça selvagem está mortaò e para tal projeto o colonizador não precisou impor batalha de sangue, apenas assistir ao seu desfilar triste (ROMERO, 1880:41). Mais expressivas são suas conclusões com relação à aplicação das leis de Darwin à análise da vida cotidiana e ao contexto cultural americano. $\mathrm{O}$ autor concluiu que:

Aplicando as leis de Darwin à literatura e ao povo brasileiro, é fácil perceber que a raça que a de vir a triunfar na luta pela vida, neste país, é a raça branca. A família selvagem e a negra, uma espoliada pela conquista, outra embrutecida pela escravidão, pouco, bem pouco, conseguirão diretamente para si (ROMERO, 1880:48).

Romero acreditava também que a disponibilidade e a engenhosidade na obtenção de recursos necessários à subsistência se voltariam em vantagens aos brancos. Prova também dessa vantagem seria o cruzamento entre os portugueses com as raças inferiores, que, ajudado pela ñmesclaò ao sangue selvagem e preto, lhes habilitaria a melhor suportar os rigores do nosso clima (ROMERO, 1880:49).

\section{Filistorínias}




\begin{abstract}
A minha tese, pois, é que a vitória na luta pela vida, entre nós, pertencerá, no porvir, ao branco; mas que este, para essa mesma vitória, atenta as agruras do clima, tem necessidade de aproveitar-se do que de útil as outras duas raças lhe podem fornecer, máxime a preta, com que tem mais cruzado. Pela seleção natural, todavia, depois de prestado o auxílio de que necessita, o tipo branco irá tomando a predominância até mostrar-se puro e belo como no velho mundo. Será quando estiver de todo aclimatado no continente. Dois fatores contribuíram largamente para tal resultado: de um lado a extinção do tráfico africano e o desaparecimento constante dos índios, e de outro a emigração europeia! (ROMERO, 1880:53).
\end{abstract}

A supremacia da raça branca, porém, só seria completa após a suplantação total das raças inferiores, a fim de melhor suportar as agruras do meio americano. O escritor elencou a ideia de raça como a causa primordial da debilidade cultural e intelectual brasileira, concluindo assim que, mesmo elevado culturalmente se comparado aos gentios ameríndios ou aos desgraçados africanos, era o português inferior a outras cepas de europeus, como, por exemplo, os anglo-saxônicos; argumentou ainda serem os portugueses pouco fecundos e não originais (ROMERO, 1880:62-63). Afiançava também que como demonstrado pela ciência, os empreendimentos políticos, poéticos, mitológicos e religiosos são guiados por aptidões subjetivas e íntimas de cada povo (ROMERO, 1880:65). Saiu em defesa também de Tobias Barreto, para quem, o modelo a ser perseguido era indiscutivelmente o alemão.

Com relação aos usos e significados da ideia de luta pela existência na produção intelectual de Romero, acreditamos haver o uso da ideia evolucionista de luta pela existência, baseado em uma concepção homogeneizadora, o que lhe conferia um significado não darwiniano. Mesmo reivindicando sua filiação ao pensamento de Darwin, ao longo de sua obra, ficou clara sua maior proximidade com o pensamento evolutivo de Haeckel. Exemplo dessa filiação seria o processo de transição entre o convívio de culturas e raças distintas (heterogeneidade) vivendo no território nacional, ao processo de mescla cultural, com finalidade a formar uma cultural brasileira (homogeneidade) ao tom da europeia. Apostava no desenvolvimento cultural e civilizacional a partir da junção das raças inferiores (ñvermelhaò e ñpretaò) e superior

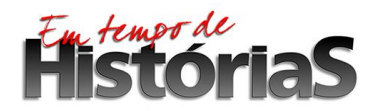

(PPGHIS/UnB) No. 34, Brasília, Jan - Jul 2019 ISSN 2316-1191 


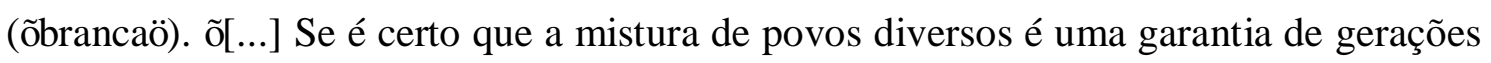
vigorosas, nenhum mais que o brasileiro pode oferecer maior vantagemò (ROMERO, 1880:156). Romero argumentava que, ñuma nação se define e individualiza quanto mais se afasta, pela história, do caráter exclusivo das raças que a constituíram, e imprimem um cunho peculiar à sua mentalidadeò (ROMERO, 1880:166-167). Ele defendia que a nação brasileira, se tem um papel histórico a representar, só o poderá fazer quanto ñmais se separar do negro africano, do selvagem tupy, e do aventureiro portuguêsò (ROMERO, 1880:167). Com relação a formação da consciência nacional, concluiu que uma nação não era projetada e sim espontaneamente formada. Advogava ainda que a conformação da consciência nacional brasileira não deveria estar pautada na glorificação do passado selvagem, defendido pelos românticos, e sim na observação atenta das especificidades das raças, do meio e do seu tempo, inspirado pelas ideias de Taine. O povo e a natureza eram os principais atributos de originalidade da nova cultura (Buckle). Apregoava também a necessidade de voltar as nossas atenções para as ideias e leis americanas (EUA) e para o criticismo (Alemanha). Dessa forma, em Silvio Romero, a literatura deveria ser observada como um sintoma de progresso ou decadência das capacidades intelectuais de um povo. Sinalizou em seu Epilogo a recepção no contexto brasileiro das novas ideias, sobretudo, as procedentes de Comte e Darwin (ROMERO, 1880:189).

A noção de luta pela existência encontra-se presente também na obra produzida por Silvio Romero em 1885, publicada no Rio de Janeiro pela editora Tipografia Universal de Laemmert, intitulada Estudos de literatura contemporânea. Argumentando sobre a obrigatoriedade do ensino primário para o concurso do progresso material e civilizacional, o autor afirmou que:

As nações modernas, com a descoberta e desbravamento de regiões inteiras desconhecidas, com a fundação de nacionalidades novas, com o aumento pasmoso da população, com a decrepitude das velhas organizações militares, com o advento de indústrias desconhecidas, viram surgir um grande número de problemas urgentes, iniludíveis, e compreenderam que na luta pela existência os seus cidadãos não teriam de então em diante a contar só com o braço: seria necessário contar antes e acima de tudo com a ideia. Daí a alta necessidade em que foi tida a instrução, daí, como arma de aperfeiçoamento e luta, o ensino obrigatório (ROMERO, 1885:142).

\section{Fististorírias}

(PPGHIS/UnB) No. 34, Brasília, Jan - Jul 2019 ISSN 2316-1191 
Nota-se que nesse ponto o autor chamou a atenção para os diversos ñavançosò ocorridos na técnica e nos saberes das civilizações modernas, o que obrigava a dispor não apenas da força braçal, bem como do uso das ideias. A luta pela existência do homem moderno não era apenas individual, como coletiva, e caberia ao Estado garantir a instrução básica, a fim de lhes assegurar condições necessárias para viverem nos novos tempos.

Com relação à influência dos fatores externos para a melhoria do homem, e consequentemente, do brasileiro em formação, o escritor sergipano, ao se opor a Araripe Junior e sua proeminência do meio físico na conformação moral e cultural do brasileiro, argumentou que os meios eram tudo para a humanidade primitiva e pré-histórica, porém, uma vez estabelecidas as raças históricas e aumentada o seu cruzamento, os povos não mais estariam submetidos ao ñjoguete dos climasò.

Há uma muralha que representa muitos milênios de luta em que a humanidade adquiriu todas as qualidades, que hoje a distinguem. Os climas passaram para o segundo plano e os agentes étnicos fisiológicos e morais tomaram-lhe a dianteira. Em nossa história o fator permanente, nos quatro séculos que já percorremos, tem sido o português. Em sua passagem para o brasileiro, há ainda um elemento etnológico $\delta$ é à mestiçagem que vamos pedir a explicação do fenômeno. O clima fica em segundo plano (ROMERO, 1885:197).

Em sua crítica a Araripe Junior, Silvio Romero prosseguiu deslegitimando aquilo que o primeiro havia elencado como uma missão da literatura contemporânea, ou seja, salvaguardar nossa memória ao retomar a história do caboclo e sua interação com o meio físico. Romero reafirmou seu compromisso em privilegiar a cepa branca em detrimento de todas as outras e nesse momento fez novamente uso da ideia de luta pela existência em suas argumentações:

Devemos desejar que em nosso país a imensa mestiçagem da população seja reforçada pelo elemento branco. Logo abaixo deste ó de justiça e verdade conferir ao negro o primeiro papel e deixar o botocudo de parte, como ser fraco, desequilibrado e prestes a extinguir-se. É a luta pela existência; o mais débil deve ser devorado (ROMERO, 1885:205-206).

\section{Fintustónias}

(PPGHIS/UnB) No. 34, Brasília, Jan - Jul 2019 ISSN 2316-1191 
Silvio Romero supõe ainda que não era possível prever, mas certamente, o próprio território americano também seria imergido em uma luta futura pela posse da terra, e que era em defesa da melhoria do mestiço que fazia uso de suas letras, a fim de garantir aos brasileiros as condições básicas para a manter manutenção e controle do país.

O que ficou claro é que Silvio Romero não encerrou o debate em torno das transformações das letras, da econômica, da cultura e da própria população brasileira, muito pelo contrário, seus diversos trabalhos vieram a somar forças junto aos debates em torno do processo de modernização nacional de fins do século XIX. A partir da identificação dos usos que o intelectual fez da ideia de luta pela existência, é possível afirmarmos que Silvio Romero esteve diretamente ligado ao processo de recepção e ajustes das novas ideias e divulgação das mesmas. Foi o próprio Silvio Romero o primeiro a afirmar que a introdução de Darwin e Comte nas discussões públicas se deu somente a partir de 1874 nas Conferências Populares da Glória, enquanto que já eram de conhecimento desde os anos de 1869 dos jovens intelectuais pernambucanos (ROMERO, 1885:96).

Em suma, vimos como o escritor sergipano fez uso da ideia de luta pela existência ao longo de sua obra, sobretudo, entre os anos de 1879 e 1895 . Veremos agora como a mesma ideia encontra-se presente em Araripe Junior, personagem também envolvido na discussão em torno da recepção e ajuste das ñnovas ideiasò europeias no campo intelectual brasileiro.

Tristão de Alencar Araripe Júnior (1848-1911) foi um jurista, jornalista, crítico literário, historiador, cronista, ensaísta, escritor, ministro do interior (1901) e cônsul brasileiro. Graduou-se em Direito em 1869 pela Faculdade de Direito de Recife. Participou ativamente da vida política e intelectual brasileira. Esteve diretamente ligado ao movimento intelectual conhecido com a ñgeração de 1870 ò ao lado de nomes como Tobias Barreto e Silvio Romero. Em parceria com José do Patrocínio, participou ativamente dos eventos políticos ligados ao movimento Abolicionista. Fez parte da fundação da Academia Brasileira de Letras em 1897 e foi um dos mais ferrenhos 
críticos literários de fins do século XIX. Envolveu-se nas mais variadas controvérsias intelectuais, sobretudo, aquelas que relacionadas às discussões em torno das ideias racionalistas, positivistas, deterministas, evolucionistas e naturalistas, sob a égide de intelectuais como Taine, Buckle, Comte e Spencer.

Ao analisarmos um conjunto de nove críticas literárias produzidas por Araripe Junior, entre os anos de 1868 e 1881, notou-se o forte interesse do autor em discutir sobre os preceitos metodológicos, estéticos e temáticos dos movimentos literários que animavam a vida cultural da Europa e do Brasil em pleno século XIX. Mostrou forte contentamento com o desenvolvimento das letras no país e a exuberância de seu meio, com especial relevo para as florestas tropicais. Afiançava a necessidade de atentarmos para as narrativas deixadas pelos viajantes naturalistas em suas respectivas descrições sobre o meio físico e os povos brasileiros. Conclamou em diversos momentos o redirecionamento da atenção na cena da literatura nacional para questões de âmbito local, em especial, os meios, os seus povos e suas interações com os espaços. Nesse conjunto de crônicas a ideia de luta pela existência encontra-se expressa nas interações do homem com o meio natural.

Com relação ao uso da ideia de luta pela existência, encontramos esparsas ocorrências, nas quais é possível inferir a utilização dessa noção. Na crônica Festival Cearense: Carta a José do Patrocínio, publicada em rodapé na Gazeta de notícias em março de 1881, Araripe Junior discutiu a luta pela existência dos retirantes da seca, dos anos de 1877 a 1879, no Ceará e saudou Patrocínio por se sensibilizar com a desgraça dos cearenses:

Diz-nos: onde fostes surpreender o segredo das nossas dores? Como um estranho se pode consubstanciar assim com os nossos pesares, como o irmão de longínquas terras pode animar-se a descer tão baixo na caverna tenebrosa aonde se agitavam os desesperos dos flagelados pela recusa da uberdade nativa? Entretanto, tu o fizestes, e, desprendendo o voo das plácidas e verdejantes montanhas do Guanabara, abandonando a paisagem confortativa do pátrio rio, fostes contemplar a enorme desgraça de um povo que se estorcia sobre a lava de um vulcão: aqui estrangulado pelas garras da fome impiedosa; ali torturado pela inconsciência da revoada dos abutres que de todos os pontos do horizonte acudiam ao aceno do anjo da morte [...] Um pesadelo. Que nome melhor pode dar-se a esse hiato horrível que o sol abriu entre os calamitosos anos de 1877 e 1879; a esse enorme soluço

\section{Alistotorias}

(PPGHIS/UnB) No. 34, Brasília, Jan - Jul 2019 ISSN 2316-1191 
em seco, sem uma lágrima que sequer orvalhasse a terra da desgraça! [...] Se há coisa que mais obumbre o pensamento nos momentos caliginosos da tormenta humana, é sentir-se a individualidade que se agita, que se diferencia do seio da matéria, de repente colhida pela engrenagem da mola universal, que lhe brada em cada átomo que se combina, em cada lei que se desenvolve:

ñO homem, nada és sem mim! Deixa-te absorver no grande todo ou deixa-te esmagar pelo meu peso!ò

Eis o verdadeiro abismo, a insondável fenda do espírito, aonde revemos nossa inanidade e de onde, por vezes, vemos sair também nossa grandeza.

Voltaste da terra do sol entristecido... E, coisa estranha! A luz, por intensa demais, penetrou-te o espírito de uma pavorosa escuridão. Luz, treva, uma e a mesma coisa! É a constante legenda da sarça ardente. O que dá a vida é o que dá a morte! (ARARIPE JR, 1881:111-112).

Há um forte lirismo na descrição do texto. Na luta pela existência, um dos maiores tormentos elencados pelo autor é certamente a individualidade frente a um problema coletivo como a grande seca de 1877 e 1879. Observa-se aqui também a importância dada aos fatores ambientais no processo de vida e de morte. Ao mesmo tempo que o sol é o responsável pela geração e manutenção da vida, ele pode se transformar em seu grande algoz. O sol abrasador é considerado o grande culpado das calamidades públicas, da fome que abatia a população, da migração forçadas das populações e da destruição da alegria do povo cearense. Nesse mesmo texto, exaltou a força da mulher sertaneja e lamentou a inconstância do clima, que levava para longe os seus filhos, em especial para ñcivilizarò o Amazonas.

Com relação as controvérsias na qual se envolveu o intelectual cearense, no ano de 1882, criticou severamente Silvio Romero em uma série de crônicas publicadas no Rio de Janeiro. Entretanto, assinaram juntos em 1883 uma crônica intitulada Lucros e perdas. Argumentam que ñforça é o que não nos falta [brasileiros]; o que resta é a consciência de que ela entra na ordem dos fatos irredutíveisò (ARARIPE JR, 1883:334). Inferirmos que a ideia de fatos irredutíveis mencionados seja a própria ideia de luta pela existência dado o teor da crônica que enfatiza que o processo de desenvolvimento de uma nação constitui-se a partir da dualidade: ganhos e perdas.

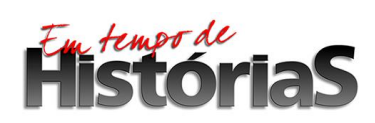

(PPGHIS/UnB) No. 34, Brasília, Jan - Jul 2019 ISSN 2316-1191 
Em sua crônica publicada em A semana, em 10 de dezembro de 1887, intitulada Literatura Brasileira, Araripe Júnior comentou a influência das ideias externas na conformação das letras nacionais. Com relação as ideias deterministas de Taine, faz uma curiosa associação entre esse crítico e o naturalista inglês Charles Darwin, afirmando que em Ensaios de crítica e história, é possível encontrar claramente o princípio de Darwin de seleção natural. O que achamos curioso é que Essais de critique et dôhistoire teve a sua primeira versão publicada em 1858, ou seja, um ano antes da publicação de The origin of species (1859), porém, sua segunda parte foi publicada em 1866, ou seja, sete anos após a publicação de Darwin. Araripe Junior prosseguiu suas arguições e afiançou a necessidade de atentarmos para as adaptações que o homem desenvolveu para enganar o meio, muitas vezes, hostil a sua subsistência. Referindo-se a Darwin, defendeu que:

[...] entre todas as causas determinantes das distribuições geográficas, nenhuma tem maior importância, do que o mimetismo, isto é, o processo instintivo de adaptação de que as raças e os indivíduos lançam mão para iludirem a natureza e não serem aniquilados por um meio hostil (ARARIPE JR, 1987:494-495).

Percebemos ao longo das diversas referências a clara sintonia entre o pensamento do intelectual cearense com as ideias de pensadores com Darwin, Spencer, Romero, e, mesmo, Aluísio Azevedo. Ao longo de seus trabalhos fez uso diversas vezes da ideia evolucionista de luta pela existência. Reservou-se a acolher a teoria de Darwin e de seus seguidores, entre eles, Spencer. Mostrou enorme afinidade com o conjunto interpretativo proposto por Buckle e Taine, porém, com suas devidas ressalvas. No primeiro caso, a negligência com as leis biológicas em detrimento das leis sociais, e, no segundo caso, a primazia do meio, da raça e do tempo, em descuido da integração do homem ao meio natural, o que chamou de excesso antropocêntrico.

Veremos agora como a ideia de luta pela existência foi percebida por outros intelectuais contemporâneos a Aluísio Azevedo e que diretamente influenciaram no campo intelectual e científico brasileiro.

\section{Fitistorias}




\section{A luta pela existência para os intelectuais brasileiros do fim do século XIX: recepções evolucionistas e ajustes das novas ideias}

É inquestionável a relação existente entre o aparecimento de The origin of species (1859) e o crescimento da discussão em torno da ideia de luta pela existência. Mesmo não tendo sido Darwin o primeiro a propor este conceito, foi certamente a partir de sua obra que esta noção ganhou maior relevo na compreensão das ciências naturais. A popularização do conceito e sua ampliação à interpretação das questões sociais aconteceu, sobretudo, a partir, dos diversos estudos de Spencer.

De acordo com Heloisa Maria Bertol Domingues e Magali Romero Sá (2003), a recepção do darwinismo no Brasil foi controversa tanto no campo científico, quanto intelectual. Consideram as autoras que a recepção das ideias de Darwin seguiu uma dupla ordem, de um lado os apoiadores e do outro os divergentes. Acreditam que o debate em torno da recepção do darwinismo, muitas vezes confundiam às ideias do próprio Darwin ao movimento evolucionista. Com relação ao spencerianismo e haeckelismo, demonstraram como exerceram forte influência nas agendas de pesquisas das principais instituições científicas brasileiras entre a segunda metade do século XIX e a primeira metade do século $\mathrm{XX}$.

Na preleção proferida e escrita por Miranda Azevedo, em 1875, e publicada no ano seguinte, intitulada Darwinismo, o autor afirmou que, assim como pensava Haeckel, o darwinismo não era mais do que um fragmento de uma lei geral de explicação dos fatos universais. Consistia basicamente de quatro leis fundamentais: $1^{\circ}$ luta pela existência, $2^{\circ}$ variabilidade das espécies, $3^{\circ}$ hereditariedade, e, $4^{\circ}$ seleção natural.

A primeira lei, aquela que por sua maior extensão talvez, e por sua ininterrompida execução nos desperta logo a inteligência é a luta pela existência, struggle for life como expressivamente chamou Darwin.

Acompanha-me, verás este espetáculo que se apresenta tal como na aparecida, onde a paz, a suavidade e a harmonia parecem ter seu domínio; pois bem, a mais tremenda luta se ostenta aí de mil variadas formas! Os combates que aí se fazem, as dilacerações terríveis que aí se passam, só podem ser contadas pelo número de organismos vivos que aí existem (AZEVEDO, 1876:57).

\section{Filsturtorias}

(PPGHIS/UnB) No. 34, Brasília, Jan - Jul 2019 ISSN 2316-1191 
Demonstrou ao longo de seu texto a capitalidade da ideia de luta pela existência para a compreensão da economia das leis gerais que geram a vida e que selecionam os mais aptos a prosseguir em seu processo de transmissão de características, e, consequentemente, a progressão e diferenciação. Continua o seu texto explicando as demais leis que compõe a interpretação de Darwin e buscou oferecer uma lição com tudo o que foi exposto: a necessidade da observância das leis gerais da biologia para o melhoramento do povo brasileiro e em especial da sua juventude a partir do estudo positivista. Miranda Azevedo foi também quem discutiu a enorme celeuma que as ideias darwinistas geraram no Brasil.

Desde que a doutrina de Darwin foi conhecida, desde que os fatos por ele interpretados apareceram explicados pela luz de uma crítica positiva, levantou-se grande celeuma, grande alarido no campo contrário, os homens da autoridade, do tradicionalismo, levantaram-se contra a nova teoria. As duas doutrinas se extremaram e feriram lutas tremendas; de um lado estava a escola teleológica, dualista que sustentava a fixidez das espécies, a criação simultânea e a destruição sucessiva das gerações, tendo a sua frente L. Agassiz; de outra parte estava a maioria dos naturalistas com Darwin, que ensinava o como e o porquê os organismos descendiam de um pequeno número de tipos universais antepassados, por meio da seleção natural. Darwin procurou basear a sua doutrina em fatores positivos, e aproveitou que os observadores por si próprio, quer os sabidos por todos, que adaptou a sua teoria; assim destruiu a acusação dôqueles que lhes diziam que sua doutrina seria uma hipótese engenhosa, porém nunca uma opinião com o cunho científico da verdade (AZEVEDO, 1876:56).

Vemos a partir dos argumentos de Miranda Azevedo a bipolarização que a ideia de Darwin gerou no meio intelectual. De um lado os defensores dos dogmas religiosos e do outro os partidários das ideias evolucionistas, grupo esse do qual Aluísio Azevedo irá fazer parte.

Além do campo científico, a ideia de luta pela existência ganhou importante relevo na produção intelectual, sobretudo, na imprensa periódica. Com relação aos registros da ideia de luta pela existência na imprensa nacional, coletamos um total de 59 ocorrências em 28 jornais, sendo que desse total, 25 foram nos periódicos da Corte 
Imperial, principalmente, no Jornal do Commercio (RJ) com sete ocorrências e $A$ gazeta de notícias (RJ) com cinco ocorrências. Porém, o tema apareceu maior relacionado com o jornal $O$ diário de Pernambuco (PE) com um total de oito ocorrências. Outro importante periódico que expõe a ideia de luta pela existência foi o Jornal do Recife (PE) com um total de sete ocorrências. Esses números são referentes ao recorte temporal de 1870-1879. Da análise dessas ocorrências, constatou-se que 42 tinham relação direta com a ideia de luta pela existência a partir dos preceitos evolucionistas, ou seja, 71,2\% dos registros.

Na edição do dia 30 de outubro de 1875, os redatores do jornal Diário de Pernambuco, publicaram na forma de editorial uma crítica intitulada $O$ darwinismo na linguagem, na qual julgam enquanto validam a apropriação da noção de luta pela existência na análise da literatura nacional e no processo de modernização das ideias. Essa crítica não foi assinada e terminou com a indicação ñdo mundo novoò. No ano seguinte, em 29 de julho de 1876, em uma crônica literária também de autoria desconhecida, intitulada $O$ futuro dos povos civilizados, seu(s) autor(es) afirmara(m) que:

[...] o darwinismo ensina que, na luta pela existência, os mais fortes e os mais hábeis devem levar a melhor e alimentar-se com prejuízo dos outros; que tal é a lei do mundo animal, e é bom que assim seja; pois destârte se opera a seleção natural. Conseguintemente, procuremos por todos os meios ser os mais fortes e tomar o lugar dos outros; teremos assim cumprido o nosso dever, pois teremos feito triunfar a lei natural que produz o aperfeiçoamento das espécies (Diário de Pernambuco, 1876:8).

Observamos aqui expressa uma clara propaganda à competição entre os indivíduos, filosofia essa ligada ao pensamento liberal. A seleção natural é vista como uma lei natural, que facilmente poderia ser transposta à análise da vida social e as formas de interação entre os indivíduos e das populações, uma vez que, era basicamente um caminho inevitável pelo qual passavam todas as espécies vivas.

Com relação às referências à ideia de luta pela existência na imprensa periódica na década seguinte, ou seja, entre os anos de 1880 e 1889, assistimos a um curioso

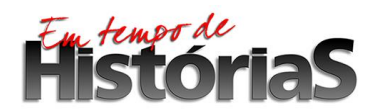

(PPGHIS/UnB) No. 34, Brasília, Jan - Jul 2019 ISSN 2316-1191 
aumento nas ocorrências do conceito. Foi coletado um total de 402 menções em 28 jornais, sendo que desses números, 358 foram nos periódicos da Corte Imperial. O maior número de registros fora, respectivamente, em o Jornal do Commercio (RJ) com 46 ocorrências, o Jornal do Recife (PE) com 45 ocorrências, o Pacotilha (MA) com 36 ocorrências, e, o Pharol (RJ) com 35 ocorrências. Do total de ocorrências, constatou-se que 284 tinham relação direta com a ideia de luta pela existência a partir dos preceitos evolucionistas, ou seja, 70,6\% dos registros. Vejamos melhor os diversos usos e significados assumidos e pretendidos da ideia entre os mais expressivos e de maior tiragem, e entre aqueles de menor tiragem e de menor circulação.

Em $1^{\circ}$ de agosto de 1882 , encontramos no Jornal do Commercio uma crônica intitulada Um concurso, no qual são expostas as arguições feitas por Tobias Barreto em seu concurso à cadeira de professor da Faculdade de Direito do Pernambuco. Observamos assinaladas suas concepções com relação à influência da ideia evolucionista de luta pela existência ao direito:

O direito não é uma entidade puramente metafísica, nem uma abstração resultante das leis da evolução, que ainda se acham em estado de incógnitas, mas simplesmente a disciplina das forças sociais, o princípio da seleção legal na luta pela existência (Jornal do Commercio, 1882:4).

O autor faz uso da ideia de luta pela existência, porém, afiançava que suas leis ainda continuam ñincógnitasò, mesmo para um homem instruído, como era o próprio personagem. Entretanto, afirmou que o direito é um princípio básico à existência, acordado e compartilhado socialmente.

Em outro periódico, ainda no ano de 1882, vemos reaparecer a ideia de luta pela existência, dessa vez na defesa da escravidão e dos fazendeiros. Vejamos:

A confecção de leis defeituosas é a consequência inevitável do erro de resolver, sem audiência da lavoura, as questões envolvendo interesses agrícolas. É preciso convencermo-nos que ninguém está mais no caso de tratar com acerto de semelhantes negócios do que os próprios lavradores.

\section{Finturtónias}


Para mostrar o pouco conhecimento prático com que os estranhos encaram estas questões, basta apontar a leviandade com que se pede a emancipação de velhos inválidos e decrépitos, assim querendo priválos e entregá-los aos azares da sorte e as duras vicissitudes da luta pela existência.

Não podemos deixar, portanto, de protestar energicamente contra o movimento irrefletido e intempestivo que se quer iniciar (Diário do Brasil, 1882:2).

Não é possível conhecer a autoria dessa reportagem, uma vez que ela não foi assinada. Nessa reportagem, publicada em 20 de dezembro, o autor incógnito advogou que a lei deveria servir como bastião à estabilidade da produção e que somente seus envolvidos $\ddot{i}$ proprietários de escravos $\ddot{i}$ poderiam versar sobre as diretrizes da escravidão. Justificou a manutenção da escravidão para os sexagenários a partir de um discurso paternalista, em que os fazendeiros são representados como protetores legais dos desvalidos. O que é importante salientar é que ao mesmo tempo em que o conceito é utilizado pelos intelectuais ligados ao movimento Abolicionista para questionar de perto a legitimidade do sistema escravista, ele foi também apropriado pelos conservadores em sua defesa do regime escravista, mostrando assim a enorme complexidade dos usos da ideia de luta pela existência e os diversos ajustes entre os intelectuais brasileiros de fins do século XIX.

Notou-se com tudo o que foi aqui analisado o forte interesse dos intelectuais brasileiros de fins do século XIX em compreender e ajustar ao seu modo os preceitos evolucionistas, em especial, a ideia de luta pela existência. Percebemos também que os usos do conceito aparecem relacionados diretamente com dois grandes temas: a migração estrangeira e a modernização intelectual e artística.

De acordo com Domingues e Sá, o Brasil pode ser considerado um país sui generis na construção da teoria darwiniana por vários motivos. Foi no Brasil que Darwin teve contato pela primeira vez com uma floresta tropical, e essa impressão o marcaria a tal ponto que, anos depois, ao comentar a construção de sua teoria, não deixou de expressar o encantamento que tal experiência lhe proporcionou. Outros fatores podem ser vistos como relevantes para a consolidação da teoria evolutiva

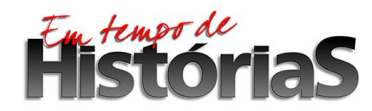

(PPGHIS/UnB) No. 34, Brasília, Jan - Jul 2019 ISSN 2316-1191 
proposta por Darwin. Foi no Brasil, especialmente a partir dos estudos de Fritz Müller, que foram coletadas as primeiras provas cabais para a validação da teoria proposta pelo naturalista inglês. Porém, os intelectuais brasileiros, sobretudo o seu próprio Imperador, também estiveram ligados ao movimento de contestação da teoria evolucionista. Considerado um dos mais entusiasmados cultivadores das ciências no Brasil durante o século XIX, D. Pedro II tornou-se conhecido em diversos circuitos intelectuais e científicos, sobretudo na Europa, graças as suas colaborações com algumas das mais prestigiadas instituições científicas europeias. Manteve contatos regulares com diversos cientistas, entre eles, Quatrefages de Bréau, um dos maiores opositores de Darwin.

Segundo Domingues (2014), predominou entre nós uma interpretação do darwinismo que destoa das ideias iniciais propostas pelo próprio Darwin, confirmando assim as proposições de Peter Bowler, sobre a predominância dos evolucionismos nãodarwinianos nas ciências de fins do século XIX e início do XX. A autora argumentou ainda que o ressurgimento do darwinismo darwiniano só ocorreu no Brasil, a partir da década de 1940 com os estudos de Theodosius Dobzhansky.

\section{Considerações finais}

Vimos ao longo deste artigo como durante o século XIX diversos eram os significados disponíveis para o conceito evolucionista de ñuta pela existênciaò tanto no campo científico quanto intelectual. Percebemos também que o Brasil estava diretamente ligado aos principais centros produtores de conhecimento na Europa, o que em muito explica a circulação entre nós de conceitos científicos no campo das ciências, nas artes, na jurisprudência e na administração pública. A ideia de luta pela existência significava não apenas as estratégias de sobrevivência de uma espécie frente aos outros de seu grupo ou externo a ele, como também para com o meio que o circundava. No Brasil a ideia foi importada do campo da biologia e serviu a diversos interesses, especialmente no que diz respeito a caracterização de seus povos e seus conflitos, bem

\section{Fitistorias}

(PPGHIS/UnB) No. 34, Brasília, Jan - Jul 2019 ISSN 2316-1191 
como na própria administração e controle dessa população ï incontrolável. O que ficou explicitado no decorrer deste artigo foi a ocorrência e os diversos significados da noção de luta pela existência no campo intelectual brasileiro em fins do século XIX, sobretudo, a partir de seu emprego na discussão em torno da modernização econômica, política, social e cultural brasileira. O evolucionismo foi a mais ecumênica revolução paradigmática ao concluir que todas as espécies vivas existentes e extintas são aparentadas com graus maiores ou menores a depender também do grau de variabilidade com relação aos seus ancestrais. O darwinismo foi o subproduto que maior celeuma provocou no campo intelectual europeu e brasileiro, especialmente a partir dos ensinamentos de Charles Darwin e Herbert Spencer ï quem primeiro extrapolou as ideias biológica para a compreensão dos agrupamentos sociais no tempo e no espaço. Homens de letras recepcionaram as ideias evolucionistas e imprimiram sobre elas novas compreensões em seus diversos usos. Silvio Romero, Araripe Junior e Miranda de Azevedo são ótimos exemplos de intelectuais oitocentistas que em seus trabalhos fizeram usos da noção evolutiva de ñuta pela existênciaò para a compreensão do Brasil e de sua população. Mesmo que cada personagem tenha divergido quanto o resultado, ambos viam o embate entre os grupos étnico-raciais como caminho inexorável em busca da síntese perfeita. O resultado dessa equação é que ao nosso ver não parece nada justo, uma vez que, eram de comum acordo entre esses intelectuais a ideia de que o elemento não-branco era indelevelmente inferior e fadado ao desaparecimento gradativo sendo o branco o mais forte perante os outros e por isso responsável pela coordenação da mistura étnico populacional. O Brasil de hoje, em pleno século XXI parece ainda concordar com essa visão errônea de superioridade, o que parcialmente explica entre nós o pavor com relação aos negros e indígenas.

\section{Referências bibliográficas:}

Jornais:

Diário de Pernambuco (1875-6)

Diário do Brasil (1882)

Jornal do Commercio (1882)

\section{Alistortorias}

(PPGHIS/UnB) No. 34, Brasília, Jan - Jul 2019 ISSN 2316-1191 
Obras:

ARARIPE JR., Tristão de Alencar. Música. Pernambuco: Correio Pernambucano, 31/08/1868. Contos da roça. Pernambuco: Correio Pernambucano, 05/10/1868.

ñDuas palavrasò In.: JAGOANHARO, Oscar. Contos Brasileiros I. Pernambuco: Correio Pernambucano, 1868. . Cartas sobre a literatura brasílica. Pernambuco: Correio Pernambucano, 17/06/1869. Juvenal Galeno. Fortaleza: Constituição, 29/09/1872. O livro de Semprônio. Fortaleza: Constituição, 29/10/1972. Escola popular. Fortaleza: Fraternidade, 21/08/1874. A poesia sertaneja. Rio de Janeiro: O globo, 11/04/1875. Cantos do Equador. Rio de Janeiro: Gazeta de notícias, 10/03/1881. . Festival Cearense: Carta a José do Patrocínio. Rio de Janeiro: Gazeta de notícias, 10/03/1881. Literatura Brasileira. Rio de Janeiro: A semana, 10/12/1887.

AZEVEDO, A. C. Miranda. Darwinismo: seu passado, seu presente e seu futuro. Rio de Janeiro: Biblioteca Nacional, 1876.

BOWLER, Peter Jr. The non-Darwinian revolution: reinterpreting a historical myth. The Jhons Hopkins University Press: Baltimore, 1992.

CAPONI, Gustavo. Georges Cuvier: un fisiólogo de museo. México: Unam; Limusa, 2008.

DAWKINS, Richard. O maior espetáculo da Terra. São Paulo: Companhia das Letras, 2009.

DARWIN, Charles. A origem das espécies, no meio da seleção natural ou a luta pela existência na natureza. Trad.: Mesquita Paul 1 vol., São Paulo: USP, 2003. . A origem do homem e a seleção sexual. São Paulo: HEMUS, 1974. A expressão das emoções no homem e nos animais. São Paulo: Companhia das Letras, 2009.

DOMINGUÊS, Heloisa; SÁ, Magali; GLICK, Thomas (org.). A recepção do Darwinismo no Brasil. Rio de Janeiro: Editora FIOCRUZ, 2003.

DOMINGUES, Heloisa Maria Bertol et al. (Org.). Darwinismo, meio ambiente, sociedade. São Paulo: Via Lettera; Rio de Janeiro: Museu de Astronomia e Ciências Afins, 2009. 2014. O darwinismo no Brasil, nas ciências naturais e na sociedade. Belo Horizonte: Rev. UFMG,

HOLMES, Brian. Herbert Spencer. v. 24. n. 3, 4.Paris: PROSPECTS, 1994.

MALTHUS, Thomas. An ensay on the principle of population. Inglaterra: Oxford University Press, 1999. MARTINS, Lilian. ñHerbert Spencer e o neolamarckismo: um estudo de casoò In.: Filosofia e história da Ciência no Cone Sul. Campinas: UFHIC, 2004.

RUSE, Michael. Mystery of myisteries: is Evolution a Social Construction?. Massachusetts: Harvard Univerity Press. Cambridge, 1999.

SPENCER, Herbert. Progresso: Suas leis e causas. Brasil: eBookBrasil, 2002. A inadequação da lei natural: Uma revisão contemporânea,1893.

ROMERO, Silvio. A literatura brasileira e a crítica moderna. Editora. (1880) Estudos de literatura contemporânea. Rio de Janeiro: Tipografia Universal de Laemmert, 1885. 1890. A História do Brasil ensinada pela biografia de seus heróis. Rio de Janeiro: Francisco Alves,

\section{Filistororias}

